Chapman University

Chapman University Digital Commons

10-1-2005

\title{
Experiential Learning Process: Exploring Teaching and Learning of Strategic Management Framework Through The Winter Survival Exercise
}

\author{
Maheshkumar P. Joshi \\ George Mason University \\ Elizabeth B. Davis \\ George Washington University \\ Ravi Kathuria \\ Chapman University, kathuria@chapman.edu \\ C. Ken Weidner II \\ St. Joseph's University
}

Follow this and additional works at: https://digitalcommons.chapman.edu/business_articles

Part of the Business Administration, Management, and Operations Commons, Business Intelligence Commons, Higher Education Commons, Other Business Commons, and the Strategic Management Policy Commons

\section{Recommended Citation}

Joshi, M. P., Davis, E. B., Kathuria, R., \& Weidner, K. (2005). Experiential learning process: Exploring teaching and learning of strategic management framework through the winter survival exercise. Journal of Management Education, 29(5), 672-695. doi: 10.1177/1052562904271198

This Article is brought to you for free and open access by the Business at Chapman University Digital Commons. It has been accepted for inclusion in Business Faculty Articles and Research by an authorized administrator of Chapman University Digital Commons. For more information, please contact laughtin@chapman.edu. 


\section{Experiential Learning Process: Exploring Teaching and Learning of Strategic Management Framework Through The Winter Survival Exercise}

\section{Comments}

This is a pre-copy-editing, author-produced PDF of an article accepted for publication in Journal of Management Education, volume 29, issue 5, in 2005 following peer review. The definitive publisherauthenticated version is available online at DOI: 10.1177/1052562904271198.

\section{Copyright}

The authors 
EXPERIENTIAL LEARNING PROCESS:

\title{
EXPLORING TEACHING AND LEARNING OF STRATEGIC MANAGEMENT FRAMEWORK THROUGH THE WINTER SURVIVAL EXERCISE
}

\author{
Maheshkumar P. Joshi* \\ School of Management \\ George Mason University \\ 210 Enterprise Hall MSN 5F5 \\ Fairfax VA 22030
}

Tel: 7039931761 Fax: 7039931870 email: mpjoshi@gmu.edu

Elizabeth B. Davis

Organizational Sciences

Columbian College of Arts \& Sciences

George Washington University

2147 F Street, Washington, DC 20052

Tel: 2029941870 Fax: 2029941880 email: ebdavis@gwu.edu

\author{
Ravi Kathuria \\ Argyros School of Business and Economics \\ Chapman University \\ One University Drive \\ Orange, CA 92866
}

Tel: 7146282703 Fax: 7145326081 email: kathuria@chapman.edu

C. Ken Weidner, II

Department of Management and Information Systems

Haub School of Business

St. Joseph's University

5600 City Avenue, Philadelphia PA 19131

Tel: 6106601647 Fax: 6106601229 email: weidner@sju.edu

Submitted to Journal of Management Education

September 9, 2003

Second Revision June 16, 2004

* $\quad$ Corresponding author 
TEACHING STRATEGIC MANAGEMENT

EXPERIENTIAL LEARNING PROCESS:

\title{
EXPLORING TEACHING AND LEARNING OF STRATEGIC MANAGEMENT FRAMEWORK THROUGH THE WINTER SURVIVAL EXERCISE
}

\begin{abstract}
In fields such as organizational behavior and industrial/organizational psychology, experiential methods have been adopted on such a widespread basis that some authors have called for dropping the distinction between experiential and traditional teaching. While intuitively appealing for teaching strategic management to traditional age undergraduate students, experiential exercise approaches have not yet become popular among strategy professors. A variety of factors have contributed to a heavy reliance on case-based teaching in the area of strategic management and business policy; this reliance has resulted in a lack of emphasis on experiential learning tools for the strategic management field. This paper examines an attempt to introduce experiential learning methods in the strategy course as a complimentary approach rather than a substitute for traditional case studies. The "Winter Survival Exercise” was used as an opening task to introduce the strategic management framework in a concise yet effective manner to 97 traditional age undergraduate strategic management students in three different sections over three semesters. Statistical analysis supported the efficacy of this teaching method. Implications for teaching business strategy are discussed in this paper.
\end{abstract}


"Although the term 'strategy' has been around for centuries, only within the past 30 years has it been applied to business and evolved as a management discipline. The entry of strategy into the lexicon of business reflected both the increasing complexity of the corporation and its environment.” (Hindle, 1994, pp. 3-4)

Over the past few decades, the field of strategic management ${ }^{1}$ has grown in complexity because the creation of the knowledge base within the field has grown tremendously. According to Fredrickson (1990), this is evident from increases in the (a) number of strategy oriented journals, (b) number of articles related to strategy in established management journals, and (c) number of new strategic management Ph.D. programs.

The increasing complexity and the rapid growth of the strategic management field have affected the teaching process in the classroom. One of these effects is increasingly intense and fast-paced courses. This complexity has also forced strategy professors to make a conscious effort to use all of their classroom "contact" time with students effectively, including the first class session, in an effort to ensure that the complex aspects of the subject are presented to students with sufficient allocation of time. Thomas (1999) expressed concerns shared by an increasing number of strategy professors regarding the effective use of that first session, arguing that "(a) the initial classroom experience sets the "tone" of the course for the semester, and (b) graduating seniors must appreciate - to the maximum extent possible - the need to break out of a "passive listening mode in order to be contributing participants in an interactive class (p.428)." We concur with Thomas' main point: Strategy faculty may be able to improve the effectiveness of their first

\footnotetext{
${ }^{1}$ As a side note, for convenience, throughout this paper, the terms "strategic management" and "business policy" are used interchangeably.
} 
day in the classroom by deploying experiential methods used widely in the field of organizational behavior and their counterparts in non-business fields, like psychology.

The purpose of this paper is to explore the appropriateness and efficacy of experiential exercises for teaching business policy, specifically for undergraduate students. We found a relatively small number of exercises specific to strategic management, and noticed a heavy reliance on case method when teaching undergraduate students. Due to these observations, we were prompted to explore methods that are complementary to case methods when dealing with these undergraduate students. Our paper explores the use of an experiential exercise in an opening class session of a business policy course to introduce traditional age undergraduate students to the strategic management framework.

\section{EXPERIENTIAL LEARNING AND TEACHING STRATEGY}

Students of business strategy - particularly traditional age undergraduate students typically do not have as much breadth or depth of real-world experience as their graduate adult counterparts. Thus, in order to be effective, learning and teaching methods for traditional age undergraduates need to "bring to life" organizational contexts that the typical student lacks in personal experience. Experiential approaches to learning might help strategy faculty fill this experience "gap.” An experiential learning process applies experience as a vehicle for learning. Also, experiential learning focuses on the process of learning as opposed to simply the content being learned (Kolb, 1984). According to Cantor (1997), experiential teaching methods help students use a multi-sensory approach towards learning a particular subject matter. A student's immersion into the subject matter through an experiential process provides a base for analysis and 
reflection that leads to learning. Experiential learning is thought to be the catalyst for an interactive process between learners. Based on his recent survey of the literature on experiential learning, Kayes (2002) concluded that there was significant value in continuing to use and refine “...experience-based approaches to management learning” (p. 137).

Similarly, Johnson and Johnson (1982) have postulated that experiential learning has the potential to impact a learner in three different ways: changing cognitive structures, altering attitudes and expanding portfolios of skills. Experiential learning has the potential to change the cognitive structures used by the learner by expanding the range of a student's life experience, thus allowing students to create their own new mental models (Argyris, 1990). Experiential learning also has the potential to alter learners' attitudes. This is especially true when discrepancies arise between learners' preconceptions and their experience. Finally, experiential learning has the potential to expand the learner's portfolios of skills because students have greater confidence in the knowledge they have discovered through an active process as learners rather than the knowledge that is presented to them when they are treated as passive students.

The use of experiential learning was developed and fostered by Lewin and his social psychologist associates as early as 1935 (Johnson \& Johnson, 1982). Johnson and Johnson (p. 16) discussed Lewin's influence on the field of experiential learning as follows:

“His (Lewin’s) research demonstrated that learning is achieved most productively in groups whose members can interact and then reflect on their mutual experiences. ... From Lewin, therefore, came an emphasis on studying one's own experiences in order to learn about group dynamics, on discussing mutual experiences with associates in order to increase mutual creativity and learning, and...in structuring learning situations." 
Based on the foregoing discussion it would seem that experiential learning methods would be highly utilized in an undergraduate strategy course. The strategy field, however, has heavily relied on a combination of texts and cases rather than experiential methods (Fowler and Scott, 1996). This field has not used experiential exercises to deliver its knowledge base, as has been done in many other sub-fields in management, such as organization theory and organizational behavior (cf., Baker \& Paulson, 1995; Bowen, Lewicki, Hall, \& Hall, 1997). In these sub-fields, experiential exercises have become highly visible contributors to knowledge delivery in college classrooms and organizational seminars (Human Synergistics/Center for Applied Research, Inc., 2002a). In organizational behavior, experiential methods have been adopted on such a widespread basis that some authors (e.g., Bowen, 1980) have called for dropping the distinction between experiential and traditional teaching.

A primary reason for the use of cases as a major tool in teaching the field of strategy is due to the established practice of using cases at the Harvard Business School as early as 1950 . The discussions about pros and cons of teaching business policy courses through cases at the Harvard Business School evolved into instructions for policy teachers by the mid 1950s (see McNair, 1954 for a detailed discussion). According to Ghemawat (1998), strategy students in the mid 1950s were taught to use cases in building their analytical skills concerning the match between a firm's policies and its competitive situation.

In the introduction of their widely used book on business policy, Bower, Bartlett, Christensen, Pearson, and Andrews (1991, p. 12) proposed that cases were the preferred method for teaching strategy: 
"The idea [of teaching through a case] is intended to sharpen the analytical skills developed in the process of case discussion. ... Such discussions should always end in the clarification of standards and criteria. The cases, we know from experience, provide stimulating opportunity for productive differences of opinion." (emphasis added)

As the strategy field developed, an emphasis on case-based instruction took root. The experiential approach, which allows for the use of personal experiences of the students, could have been applied as either an alternative or a complementary teaching tool to the case based approach of delivering strategy concepts to the students. We posit that this emphasis on teaching strategy through a case based approach might have discouraged experiential approaches in teaching strategy.

Argyris and Schön's (1974) work posits that assumptions lead to forming filters that prevent different ways of thinking from entering a person's consciousness. The lack of existing materials for using experiential exercises to teach strategy suggests that experiential methods may have been "filtered out" due to assumptions about learning held by strategy faculty. Few experiential exercises exist that are specifically designed for strategy course content (Human Synergistics/Center for Applied Research, Inc., 2002b). Strategy texts that promote and offer “experiential exercises," upon closer inspection, are in fact relying largely on using case methods.

To illustrate this point, consider a book of “exercises” by Edge (1995) which was created to teach strategic management. This book requires students to use role-playing to analyze specific business cases (which have already occurred) through a strategic management framework. Thus, the "exercises" in this book still require the use of predetermined strategy-specific content. In a more recent book, Siciliano and Gopinath (2002) include many reflective exercises to introduce 
strategy concepts, but ground those exercises in a series of mini-cases. In a similar fashion, Kemper (1989) includes an "experiential component” in a text's accompanying study guide. This study guide also relies extensively on mini-cases as the vehicle to illustrate strategic management concepts and processes. In all these books the mini-cases do not meet the three criteria necessary for experiential learning listed by Johnson and Johnson (1982). Based on the authors’ combined experience in teaching strategy, it is felt that the above referenced resources represent a "highwater mark" in terms of experiential material for teaching the subject.

Other authors (Fowler and Scott, 1996) raised concerns regarding the pervasive use of cases to teach strategic management. As they are customarily used, most cases do not permit interaction among groups - a necessity in decision making processes in present day strategic issues (Hitt, Ireland, \& Hoskisson, 1997). Fowler and Scott’s concerns centered on: (a) limited availability of data and information about cases, (b) many cases being outdated, and (c) the limited ability of cases to expose students to all possible aspects of the strategic management framework. In summary, case-based teaching strategy for undergraduates may be ripe for a reexamination. The need to explore new supplemental teaching methods in business policy is primarily due to the growth of the field. The strategy field has become more complex, making effective use of classroom time increasingly important, and though cases help traditional age undergraduate students with the assessment of many situations, cases alone are insufficient in 'bridging” the gap between these students' knowledge, experience, and their preparation for the real world. 
Thus, in this paper we explore the use of experiential exercises in undergraduate strategy classrooms - exercises that may complement the predominant case method for learning strategic issues. In particular, we consider that the experiential exercises might expose traditional-age undergraduate students to the strategic management framework. This would allow for reflective interaction where students could learn from each other's shared, lived experience - even if that experience was in the classroom. In the following section we explore how a well-established exercise in another sub-field of management might be used to achieve a successful introduction of the strategic management framework to full-time traditional age undergraduate students and, in the process, make the use of the first class session more effective.

\section{THE “WINTER SURVIVAL EXERCISE”}

The Winter Survival Exercise (WSE) was originally developed primarily as a teaching tool for understanding the dynamics of team building, group decision making, and problem-solving. In some instances, this exercise was used to understand the critical implications of communication in the team building process (Johnson \& Johnson, 1982; Baker \& Paulson, 1995). A version of the WSE used by Johnson and Johnson, with instructions for participants and debriefing/facilitation notes, is included in the Appendix.

\section{Purpose and Use of the WSE}

Prior to the classes described in this study, two of the authors had experimented with the WSE (as described in Johnson \& Johnson, 1982: 111-116; some examples of similar "survival exercises" can be found in Bowen, et al., 1997; Gordon, 1995; Lafferty, 1974; and Lewicki, Bowen, Hall, and Hall, 1988). The authors' initial use of the WSE was to teach team concepts to incoming 
MBA students in an orientation program. After facilitating the MBA orientation several times, the authors reached the conclusion that the WSE might have potential for teaching the basic concepts of strategic management to traditional age undergraduates if modifications were made to the debriefing of the exercise.

When considering the usage of the WSE in an undergraduate strategy course, the authors desired to shift the learning objectives of the exercise from group functioning and decision making to an introduction to the strategy management process. One of the authors used the WSE in the first session of a strategy class as a pilot study. The pilot was assessed in terms of (a) the viability of an exercise like the WSE in teaching strategic management concepts, and (b) the efficacy of teaching strategy using this method. Based on the experience in the pilot, the authors further refocused the debriefing of the exercise and used it in the first class session of traditional age undergraduate strategic management courses in three subsequent semesters.

\section{Conducting the Exercise}

In its original form, the WSE is designed to provide the learner with a basic understanding of group problem solving (Johnson \& Johnson, 1982). First, participants read the exercise, in which they are put in the situation of having survived a mid-winter crash-landing of a plane in Minnesota. Participants are asked to individually rank fifteen items in order of importance, a reflective component of experiential exercise.

Once all participants have completed their individual rankings, they are placed in groups of 5 to 9 people, and are asked to rank the same fifteen items in order of importance as a group this is the shared experience portion of the exercise. Once the group rankings are completed, the 
exercise allows participants to compare their individual outcomes with group outcomes, relative to an "expert's" set of decision choices. A lower score indicates decisions that are closer to those provided by the "expert.” After groups have completed the exercise, the facilitator leads a discussion which focuses on effective group problem solving, team building, and communication, thus altering participants' cognitive structures (Johnson \& Johnson, 1982). As originally intended, this exercise is very useful in illustrating the importance of effective team processes; by comparing individual and group scores. In most instances, individual scores tend to be higher than the "teams score." Similarly, the mean individual score tends to be higher than the average team score (a lower score indicates better decisions). No special materials are required for students beyond the brief written information outlining the situation, a pencil, and movable chairs. The complete exercise takes about 60 - 90 minutes.

Revised Debriefing. The authors decided to explore the effectiveness of the exercise - as revised - to teach the concepts of strategic management. The plane crash situation presents both the individual and group with a complex problem involving strategy building. This process generally parallels the method of strategy building in organizations because - based on the choice of different strategies and resources - there are various outcomes in the exercise. Analytically, individuals and groups are faced with a problem that requires them to think through their actions and apply a basic model for building strategy. Because participants' decision options in the WSE are made within the context of earlier decisions, the exercise parallels "path dependency" in strategy building (cf. Madhok, 1997). In addition, the decision steps in the WSE provide an 
illustration of strategy concepts, at both an individual and group level. Both path dependency and the relationship of strategy concepts to the WSE are depicted in Figure 1.

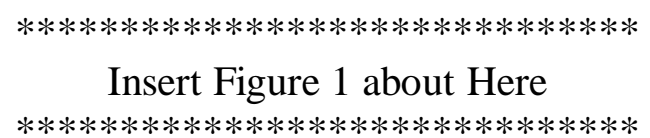

Figure 1 depicts three different decision points. The first decision point focuses on understanding the mission and goals as well as availability of strategic choices. The second decision concerns evaluation of external threats and opportunities as well as the evaluation of internal strengths and weaknesses. The final decision point illustrates the mechanisms of strategy implementation and strategy control. Using this approach, students were introduced to the five major strategy concepts during the debriefing session as a prelude to the main body of the strategic management course. These are missions, goals, values and principles; strategic choice and strategy formulation; external and internal analysis; strategy implementation; and strategy evaluation and control. During the debriefing, the authors provided a brief lecture about the strategic management framework, explaining to students the process of strategic decision making. As the instructors explained the links between decision processes and strategic management, students quickly realized that they understood (albeit implicitly) the strategic management framework.

Mission, goals, priorities and values. The scenario of a winter crash landing in Minnesota calls for students (first individually and, then later, as a group) to agree on what their group’s mission/goals and objectives were, either to stay put and be found or move and find their destination. The relative importance of the 15 items in the exercise changes drastically depending 
on this decision of "whether to go towards the destination or to stay put" as indicated in the Appendix:

"The eighty miles to the nearest known town is a very long walk even under ideal conditions, particularly if one is not used to walking such distances. Under the circumstances of being in shock, dressed in city clothes, having deep snow in the woods, and a variety of water barriers to cross, to attempt to walk out would mean almost certain death from freezing and exhaustion.”

Thus, this decision point establishes a frame of reference for the group as it makes subsequent choices. As a first step in the strategic management process, establishing an organization’s mission and objectives are critical actions. Once established, the mission guides future decisions.

Strategy formulation and strategic options/choice. The groups must make a diagnosis about their current situation comprising both the external environment and their group’s internal capabilities. This diagnostic work lays the foundation for the formulation of a set of strategic options. Potential options might include:

- $\quad$ Hiking out of the plane crash area together.

- $\quad$ Deciding to stay put for signaling purposes.

- $\quad$ Deciding to stay put for physical survival purposes.

The above mentioned options are not meant to be exhaustive, but to illustrate the possible strategies which might be generated. These alternatives can be weighed and analytically evaluated by each group to form the basis for a final choice of strategy (note that selection of a different strategy would likely reflect differently on the scores of each group).

SWOT - environmental/internal assessments. Having formulated the objective "to go or to stay” and selecting a strategic option, the groups might then decide to process the external information (in terms of opportunities and threats) and assess their own internal capabilities (in 
terms of strengths and weaknesses). For example, external scanning would include gathering and processing data regarding (but not limited to) such variables as the cold weather, the surrounding woods, the time of year, time of day, depth of the snow, and the height of the surrounding mountains. The groups must also then begin to gather and process data about their own internal strengths and capabilities, as well as their potential weaknesses. These characteristics of the situation might include (but not be limited to) the extent of injuries suffered by those who survived the crash, the physical strength of the survivors, the amount of food they possess, and an inventory of their other belongings and available equipment. Implicit in the assessment and implementation processes is the assumptions made and used by the participants about the data and factors available to them.

Strategy implementation. Implementation of the chosen strategy requires allocation of resources. In the WSE, groups are asked to individually rank fifteen items at the crash site in order of importance and then to achieve a consensus on the rankings. Groups invariably use the strategy that they have developed and chosen as the basis for determining which items are most important. For instance, if a group chooses to leave the crash site, they are more likely to consider the compass a critical resource than others. Alternately, if a group chooses to stay and remain warm, they are more likely to consider the cigarette lighter a more important resource as it can help generate a fire. Finally, if a group chooses to stay and hopes to signal potential rescue groups, the gun would increase in importance, as gunshots could be used as a signaling device that would assist a search team looking for the crash survivors. 
Strategy evaluation. Formulation and implementation of strategy cannot be effective in the absence of evaluation that determines the appropriateness of the strategy that has been chosen (Drucker, 1966). In this exercise, the evaluation is part of the debriefing. During this debriefing, the groups' and the individuals' rankings of the fifteen items are compared to those of a "wilderness expert." The process represents a closing of the feedback loop in the strategic management process. This forms the basis for in-class discussion of (a) the use of both qualitative and quantitative measures of performance to maximize objectives, (b) the concept of intended and unintended consequences, and (c) the potential need to take corrective action. Additionally, the process of comparing their rankings to an "expert's" rankings serves the purpose of connecting their objectives and goals with the strategic management process. According to Figure 1, debriefing allows the students control because they are then able to receive feedback as to the likelihood of finishing their mission. Also, comparison and benchmarking with an expert is an important part of the evaluation process. These ideas are critical aspects of striving for the "fit" between different components of the strategy management process.

Concomitant Outcome (Process Issues). The value of having both individuals and groups complete the exercise does not go unnoticed by students. The reflective process of comparing individual rankings to the group's rankings provides an opportunity to introduce the idea of the criticality of individual contributions to make a strategy successful. Authors in the strategy field indicate that effective strategic management in organizations requires participation from all levels of the organization, and acknowledges that a group approach toward formulating strategy is critical (Hitt et al., 1997; Jauch \& Glueck, 1988; Thompson \& Strickland, 1995). The 
debriefing session provides an opportunity for discussion of these strategy/content-related issues to take place. Also, the debriefing related to the scoring mechanism reinforces the value of a group approach toward decision making and problem solving, and provides concrete measurement in the form of scores to reinforce this point. For instance, a comparison of individual scores vs. group scores can demonstrate the overall effectiveness of groups - for better or for worse - in the quality of decision making. In addition, both groups and individuals learn the importance and value of leadership and communication in the decision making exercise, and the value of building into a decision the means to gauge its effectiveness (Drucker, 1966). Thus, instructors have an opportunity to emphasize the role of people in the strategic management process; consistent with strategy researchers (e.g., Floyd \& Wooldridge, 1992, 1994) who have argued that human dimension plays a critical role in successful formulation and implementation of strategies. It is possible that the WSE can illustrate how human interaction and decision processes can be further incorporated into not only the strategic management literature but also the strategy classroom.

\section{RESEARCH QUESTIONS: EFFICACY OF THE WSE IN A STRATEGY COURSE}

As stated earlier, the WSE was originally developed to facilitate team building and communication skills. In this study, we sought to evaluate the efficacy of the WSE with respect to introducing strategic management concepts in an undergraduate strategy course. To accomplish this task, we developed the following research questions:

RQ1 Does the WSE help students learn strategy concepts?

RQ2 Does the successive use of the WSE (i.e. repeated practice) to teach strategy concepts correlate with improved effectiveness on the part of the instructor as observed through the student responses of the WSE test? 
RQ3 Does the WSE facilitate greater learning of some strategy concepts more than other concepts and, if so, which ones?

\section{METHODS}

\section{Sample}

Data were collected over three semesters from 97 full-time traditional age undergraduate students in a business policy class. The course was taught in an AACSB-accredited business school in a selective Catholic liberal arts university with a relatively homogeneous undergraduate student body with respect to race and ethnicity. Subjects' gender and major are reported as Table 1; in general, the sample was relatively homogenous because the groups of students studied for this article were all senior students who had completed their core business curriculum. Semesters 1, 2, and 3 had 31, 35 and 31 students respectively.



Each class of students was introduced to the WSE on the first day of the semester by one of the authors (the same author taught all three sections). Approximately an hour and a half of class time in a two and one-half hour class was devoted to the exercise. Students were asked to form groups of 3 to 5 students with classmates of their own choice; and the exercise was conducted as originally designed. The debriefing session was conducted as described in an earlier section, wherein the basic concepts of strategic management process as illustrated in the WSE were discussed (see Figure 1). 


\section{Measures}

To test the efficacy of the revised WSE debriefing (i.e., with the focus on the strategy framework) and the relationship between the WSE and student learning, the instructor included one question in the students' midterm examination. This essay question asked students to explicate their knowledge and understanding of the WSE as an illustration of the strategic management process. All 97 students over 3 semesters responded by answering this essay question, describing the knowledge they gained about the strategic management process as a result of their participation in the WSE during the first class session. To be fair to the students, the midterm grades of students were calculated without considering the answers from the survival exercise question.

\section{Data Collection}

The instructor did not discuss or talk about the WSE in class after the first session. Students were not reminded to study the material on the WSE when the midterm examination was discussed. This procedure provides an extremely conservative evaluation of the efficacy of the WSE. The question asked to students during the midterm examination was very much a "top of mind" response which would indicate some level of learning. Thus, any positive results can be reasonably interpreted as indicative of learning from the first session's experiential exercise.

Framing of the Test. The test was an essay-based question:

"Based on your experience with the WSE on the opening day of the class, please elaborate on the concepts of strategic management and how the WSE helped you to understand these concepts." 
The instructor read the answers and identified the underlying concepts even when the traditional strategy vocabulary was not used by the students. For example, at the time when the test was conducted, the students were not exposed to the theoretical framework of implementation and evaluation of strategy, yet these concepts were presented by students in their answers using nontechnical language. Thus, the test question focused on demonstrating and understanding the concepts rather than the content related memory based answers of the debriefing of the WSE. For our analysis, we planned to use only the answers of students who were present on the first day. During one semester, one student was absent, so her answers were excluded in our analysis.

\section{Content Analysis}

The students' essay answers were examined; a content analysis was performed to assess students' learning with regard to the five major components of strategic management. As a first step, the authors of the paper made a list of possible strategy concepts that could be created by students based on the debriefing of the WSE and its link to the strategy framework as shown in Figure 1. This framework is consistent with the prevailing literature and models in the field of strategic management and as such, any instructor in the field replicating our exercise would be able to draw up a list very quickly. The second step involved an independent review of student answers by two coauthors, one of them being the instructor who administered the WSE to the students. The next step involved both authors arriving at a consensus about the classification of the content. We used a pseudo-Delphi approach was used to codify the answers and ensure a high level of interrater reliability. There was very little difference in the independent classification of both authors. Whenever differences arose (less then 10\%), the authors reasoned with each other about their specific classification of an 
answer. Subsequently they went back to the student's answer and examined the answer together to reach a consensus.

The content analysis included the recording of multiple responses in each student essay. The responses by students were tabulated to assess the number of times a particular topic was indicated as learned by a student. Tables $2 \& 3$ provide these data for all five topics across three semesters as well as a cumulative count. The data thus collected were further analyzed using the tests of proportions described in the next section.

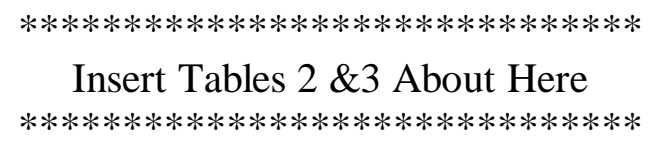

\section{RESULTS}

\section{Does the WSE Help Students Learn Strategy Concepts?}

Across three semesters, answers from all the students were classified as either having (a) learned at least one strategic management concept through the WSE, or (b) learned no strategic management concept through the WSE. Thus, the null and alternative hypotheses ${ }^{2}$ for RQ1 were:

Hypothesis $1_{0}$. The proportion of students learned at least one concept is less than or equal to 0.5

Hypothesis $1_{1}$. The proportion of students learned at least one concept is greater than 0.5

The "test of proportions" was used to evaluate the data. Based on this analysis, the proportion of students reporting no learning was $0.23\left(\mathrm{p}_{1}=22 / 97\right)$ and the proportion of students reporting having learned at least one concept was $0.77\left(\mathrm{p}_{2}=75 / 97\right)$. The $\mathrm{Z}$ value for observed proportions

\footnotetext{
${ }^{2}$ Please note for the rest of the manuscript, the alternative hypotheses are not listed. They are only reported in Tables 2 and 3.
} 
was $5.32(\alpha=0.05)$ which was greater than the critical value $1.645(\mathrm{p}<0.001)$. Thus, we reject the null hypothesis and find support for the alternative hypothesis that students do learn strategic management concepts though the WSE.

\section{Does the Instructor's Teaching Improve from Repeated Uses of the WSE to Teach Strategy Concepts?}

In the use or evaluation of any pedagogical tool it is important to consider whether the instructor develops a knowledge base that allows the instructor to be more effective and efficient over successive uses of those mechanisms. This research question was examined from two perspectives (a) if there was an improved effectiveness present from one semester to the subsequent semester, and (b) if there was a presence of effectiveness demonstrated by the instructor over a longer period of time (three semesters). Since data were available for three semesters, three tests of proportion were conducted. Comparisons between semesters 1 and 2, as well as between semesters 2 and 3, were conducted to assess an immediate improvement in effectiveness, whereas comparisons between semesters $1 \& 3$ were conducted to assess the improved effectiveness over repeated uses of the WSE.

Thus, the null hypotheses for RQ2 are:

Hypothesis 2a. The proportion of strategy concepts learned by students in semester 2 is less than or equal to the proportion of strategy concepts learned by students in semester 1.

Hypothesis $2 b$. The proportion of strategy concepts learned by students in semester 3 is less than or equal to the proportion of strategy concepts learned by students in semester 2. 
Hypothesis 2c. The proportion of strategy concepts learned by students in semester 3 is less than or equal to the proportion of strategy concepts learned by students in semester 1.

We calculated the proportions of the total number of strategy concepts reported as learned by all students to the total maximum number of strategy concepts that a class could report as learned (i.e., number of students in a class multiplied by 5 strategy concepts). The "test of proportions" was used to evaluate the data. For each semester, the proportions of total reported concepts to total possible concepts were $\mathrm{p}_{1}=0.30, \mathrm{p}_{2}=0.41$, and $\mathrm{p}_{3}=0.49$ respectively for semesters 1,2 , and 3. The scores of $Z$ values for each comparison are given in Table 4. Based on these results ${ }^{3}$, we found no evidence of a semester-to-semester improvement in the effectiveness measure. However, perhaps more importantly, there is a likely demonstration of improved effectiveness over a longer period of time as evidenced in the comparison between semester 1 and semester 3.

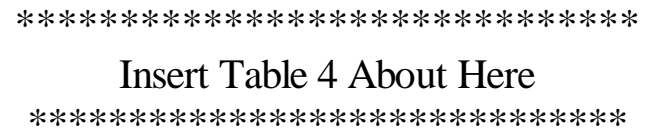

\footnotetext{
${ }^{3}$ It should be noted that the approach we have taken to measure the instructor effectiveness might have some limitations due to a few drawbacks. Our approach suggests that if each new set of students identify more strategy concepts over time and semesters, then it is likely that the teacher has benefited from the repeated use of WSE in teaching strategy concepts. It may be possible that repeated applications of the WSE by the instructor sets up the conditions for practice based learning. For instance in our experience we found that the debriefing became more elaborate in later semesters as compared to early semesters. Secondly, we also learned to better manage the group processes relative to the creation of teams. However, the limitation of our approach is that improved scores by new sets of students in later semesters could be an outcome of informal student channels about the use of WSE in the introductory class. Hence, we wish to interpret results from this test very cautiously. Ideally, there should have been a direct test of effectiveness of the instructor, however since we lack such data we settled for the indirect approach. We thank both the anonymous reviewers for identifying this limitation in the interpretation of our work.
} 


\section{Does the WSE Facilitate Greater Learning of Some Strategy Concepts More than Others}

\section{Do and, If so, Which Ones?}

The WSE may have greater efficacy in terms of students’ learning of some strategy concepts than other concepts. The five strategy concepts are indicated in Table 1 . The raw data in Tables $2 \& 3$ indicated that strategy formulation was by far the most reported concept, followed by mission, goals, values and principles (MGPV). Also the same table indicates that students reported SWOT analysis the least times as a topic learned through this exercise. We, therefore, propose to test the most reported concept - Strategy Formulation - with the remaining four concepts. We also wanted to test if the least reported topic was significantly less learned in comparison to the second most learned topic, i.e., MGPV. Thus, the null hypotheses for RQ3 were:

Hypothesis 3a. The proportion of students learning strategy formulation is equal to the proportion of students learning strategy implementation.

Hypothesis 3b. The proportion of students learning strategy formulation is equal to the proportion of students learning strategy evaluation.

Hypothesis 3c. The proportion of students learning strategy formulation is equal to the proportion of students learning mission, goals, principles and values (MGPV).

Hypothesis 3d. The proportion of students learning strategy formulation is equal to the proportion of students learning SWOT.

Hypothesis 3e. The proportion of students learning MGPV is equal to the proportion of students learning SWOT.

We calculated the proportion of the total number of times students report a strategy concept in semester 3 to the total number of students enrolled in semester 3. Only semester 3 data 
was used as a control for the learning curve effect found in RQ2. The average proportions were compared, as indicated in Table 5.

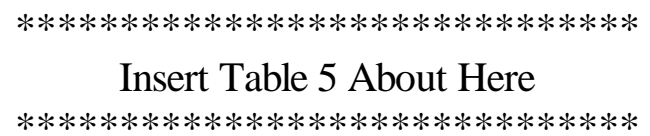

To examine for statistical differences that may exist in reported learning by students among the five strategy concepts, we conducted a pair-wise comparison of proportions. The results provide support for the idea that the WSE contributed to very strong understanding of the concepts of both MGPV and strategy formulation relative to other strategy concepts.

\section{DISCUSSION}

The findings of this study provide evidence to indicate that the use of the Winter Survival Exercise with a modified debriefing was an effective method for introducing traditional-age undergraduate students to strategic management concepts. The concepts related to MGPV, strategy formulation and strategy implementation were notions that clearly were learned on the first day of class through the use of the WSE. Further, as reflected in their midterm examination essays, students learned (a) concepts including strategy evaluation and control, and (b) SWOT analysis as a result of participating in the exercise on the first day of the strategy class. The findings of this study suggest that the Winter Survival Exercise, as adapted, may have significant value as a method for introducing students to strategic management concepts. The exercise appears to facilitate students' learning in terms of all five critical components of strategic management field. However, we must emphasize that our conclusion is not that faculty should use 
experiential exercises in lieu of cases to teach strategy. We disagree with Locke’s (2002) conclusion that "The case method, by itself, is useless." (p. 199, emphasis in original document). Instead, we suggest that teaching of strategy management through cases may be complemented by the addition of a few experiential exercises. Strategy faculty might find that exercises such as the one presented here could be useful in introducing concepts or sections of a course to traditionalage undergraduate students who lack a substantial body of work experience. By using cases, experiential methods, and other forms of pedagogy, faculty are more likely to create a learning environment in the classroom that appeals to a broader range of learning styles and hence may support a broader range of students. Thus, we suggest that strategy faculty appropriately use both inductive (e.g. cases) and deductive (e.g., experience-based) approaches to learning when teaching strategy management to undergraduate students.

As with any study, these results should be interpreted with some caution based on the study's limitations. The first of these limitations is whether these results are generalizable based on one instructor's choices in teaching or, perhaps more accurately, teaching emphasis in the debriefing of the exercise. Second, while students were asked to respond specifically on their midterm examination, one cannot definitively say that a cumulative learning effect was not at work. By the date of the midterm examination, students had been exposed to approximately 7 weeks of strategic management material. This exposure to the subject matter might explain student responses about early parts of the strategy framework (i.e., MGPV and strategy formulation). It does not, however, account for student responses on issues of strategy implementation or evaluation. Both these were concepts explored by the instructor in the 
debriefing session of the Winter Survival Exercise, but students were not yet introduced to this material by the time the midterm examination was administered. Finally, the efficacy of the proposed exercise is not compared with a control group. This limitation was, however, remedied to some extent by deploying some conservative tests of proportions. For example, while testing the H1, the alternative hypothesis' were to be supported only if the proportion of students that learned a concept was greater than 0.5 .

Despite these caveats, the results revealed that students assimilated the basic concepts of the strategic management process. Other teachers of strategic management might create, apply, or adapt experiential exercises for use in strategy classrooms, and it is likely to be effective. Future research could replicate this study, and test that argument in other settings, both in terms of institutions and faculty members teaching the course.

Other future research might explore the relative efficacy of different but similar "survival" exercises in terms of students' learning of strategy concepts. In addition, if different teaching methods are more effective at helping students learn different strategy concepts, there is potentially valuable research to be conducted exploring the value of using multiple teaching methods in the same course.

This adaptation of a survival exercise contributes to improvement in the teaching of strategic management in at least two distinct ways. First, we have begun to address the lack of experiential exercises in the field of strategic management and, further, the evaluation of the efficacy of such exercises for the strategy field. Second, our experiment offers a way to use the first day of an academic semester in a highly engaging way while acquainting students with the 
elements of a strategic management framework. In addition, the findings of this study suggest that strategy faculty consider experiential exercises as part of their pedagogy - in combination with other teaching methods - to maximize the effective use of limited classroom time, particularly in the first class session.

Instructors interested in using the WSE in their first session of a strategy course for traditional age students need to address some common problems and issues. As we conducted this exercise over three semesters we discovered some issues that needed to be overcome to enable the smooth operation of the exercise in addition to learning from the exercise. These are as follows:

1. Make sure that the students forming groups are from different majors. This allows an instructor to create cross-disciplinary teams to validate the concept that business policy is an integrative course.

2. Consistent with the original instruction of conducting any survival exercise, if a student is found to be familiar with such an exercise (surviving in the desert, the NASA exercise, etc.), then that student needs to be assigned as an observer rather than a participant. This student reports the observations the group dynamics during the debriefing session.

3. The students were seniors who had completed all the core courses prior to enrolling into this class. If an instructor has access to student emails, it would be advisable to send an advance email to students notifying them that attendance in the first class is critical.

4. We were careful to present answer keys in power point format so that no hard copies were circulated to the students. This would ensure the integrity of the exercise if an instructor wishes to use it repeatedly.

5. The exercise and debriefing process works well in a 2 hour 40 minute class and at the very least can be conducted in 1 hour 15 minute class. Less time than this is inadequate for debriefing which is where the idea of strategy management framework is introduced.

In a recent article, Burke and Moore (2003) suggest that the question of student motivation should be considered as paramount prior to any discussion concerning instructional effectiveness. Further they suggest that instructors must adjust their teaching methods across differing subject material and student levels. Our findings in this regard suggest that faculty teaching strategy to traditional-age undergraduate students must be also aware of such issues. This is because faculty 
teaching strategy management to traditional age undergraduate students face a number of challenges; chief among these challenges is students' lack of experience with business decision making. With a variety of teaching methods, including a combination of experiential exercises, cases, lectures, simulations, and others, the "typical” strategy classroom of tomorrow may look very different than that of today. The time may have come for greater use of experiential exercises in the strategy classroom, and for research exploring the potential efficacy of those exercises. 


\section{REFERENCES}

Argyris, C., \& Schön, D. A. 1974. Theory in practice. San Francisco: Jossey-Bass.

Argyris, C. 1990. Overcoming organizational defenses. Boston: Allyn and Bacon.

Baker, H. E., \& Paulson, S. K. 1995. Experiential exercises in organization theory. Englewood Cliffs, NJ: Prentice Hall.

Bowen, D. B. 1980. Experiential and traditional teaching of OB: A dubious distinction. Exchange: The Organizational Behavior Teaching Journal, 5 (2): 7-12.

Bowen, D. D., Lewicki, R. J., Hall, D.T., \& Hall, F. S. 1997. Experiences in management and organizational behavior. New York: John Wiley \& Sons.

Bower, J., Bartlett, C., Christensen, C. R., Pearson, A., \& Andrews, K. 1991. Business policy: Text and cases. Burr Ridge, IL: Irwin.

Brah, A., \& Hoy, J. 1989. Experiential learning: A new orthodoxy? In S. W. Weill \& I. McGill (Eds.), Making sense of experiential learning: 70-77. Philadelphia: Society for Research into Higher Education and Open University Press.

Burke, L. A. \& Moore, J. E. 2003. A perennial dilemma in OB education: Engaging the traditional student. Academy of Management Learning and Education, 2 (1):37-52.

Cantor, J. A. 1997. Experiential learning in higher education. Washington, DC: ERIC Clearinghouse on Higher Education.

Drucker, P. F. 1966. The effective executive. New York: Harper \& Row.

Edge, A. 1995. Exercises in strategic management. Honolulu, HI: System Logistics, Inc.

Floyd, S. W., \& Wooldridge, B. 1992. Middle management involvement in strategy and its association with strategic type: A research note. Strategic Management Journal, 13: 153167.

Floyd, S. W., \& Wooldridge , B. 1994. Dinosaurs or dynamos? Recognizing middle management's strategic role. Academy of Management Executive, 8 (4): 47-57.

Fowler, K. L., \& Scott, D. M. 1996. Experiential learning in the capstone strategic management course: Collaborative problem solving, the student live case, and modeling. Journal of Business and Management, 3: 103-120.

Fredrickson, J. W. 1990. Perspectives on strategic management. New York: Harper and Row.

Ghemawat, P. 1998. Strategy and the business landscape. Reading, MA: Addison-Wesley.

Gordon, J. R. 1995. Organizational behavior: A diagnostic approach. Englewood Cliffs, NJ: Prentice Hall.

Hindle, T. 1994. Field guide to strategy. Boston: Harvard Business School/The Economist Reference Series.

Hitt, M. A., Ireland, R. D., \& Hoskisson, R. E. 1997. Preface. In T. B. Palmer (Ed.), Insights: Readings in strategic management. Minneapolis: West Publishing Company.

Human Synergistics/Center for Applied Research Inc. February 25, 2002a. http://www.hscar.com/spc.htm.

Human Synergistics/Center for Applied Research Inc. February 25, 2002 b. http://www.hscar.com/subarctic.htm. 
Jauch, L, \& Glueck, W. 1988. Business policy and strategic management. New York: McGraw Hill.

Johnson, D. W., \& Johnson, F. P. 1982. Joining together (2nd ed.). Englewood Cliffs, NJ: Prentice Hall.

Kayes, D. C. 2002. Experiential learning and its critics: Preserving the role of experience in management learning and education. Academy of Management Learning and Education, 1: $137-149$.

Kemper, R. 1989. Experiencing strategic management. Fort Worth, TX: The Dryden Press.

Kolb, D. A. 1984. Experiential learning. Prentice-Hall: Englewood Cliffs, NJ.

Lafferty, J. C. 1974. Subarctic survival situation. Plymouth, MI: Human Synergistics International.

Lewicki, R., Bowen D., Hall, D., \& Hall, F. 1988. Experiences in management and organizational behavior. New York: Wiley \& Sons.

Locke, E. A. 2002. The epistemological side of teaching management: Teaching through principles. Academy of Management Learning and Education, 1: 195-205.

Madhok, A. 1997. Cost, value and foreign market entry mode: The transaction and the firm. Strategic Management Journal, 18: 39-61.

McNair, M. P. 1954. The case method at the Harvard Business School. New York: McGrawHill.

Rutstrum, C. 1973. The new ways of wilderness. New York: Collier.

Siciliano, J. I., \& Gopinath, C. 2002. Strategize: Experiential exercises in strategic management. Cincinnati: South-Western Thomson Learning.

Thompson, A, \& Strickland, A. 1993. Strategic management: Concepts and cases (7th ed.). Burr Ridge, IL: Irwin. 
Figure 1. Winter Survival Exercise and Strategic Management - Debriefing




Table 1

\begin{tabular}{|c|c|c|c|c|}
\hline \multicolumn{5}{|l|}{ Participants } \\
\hline & Semester 1 & Semester 2 & Semester 3 & Total \\
\hline \multicolumn{5}{|l|}{ Gender } \\
\hline Male & 16 & 25 & 19 & 60 \\
\hline Female & 15 & 10 & 12 & 37 \\
\hline \multicolumn{5}{|l|}{ Major } \\
\hline Accounting & 4 & 3 & 5 & 12 \\
\hline Information Systems & 3 & 0 & 2 & 5 \\
\hline Finance & 9 & 3 & 10 & 22 \\
\hline Marketing & 11 & 24 & 10 & 45 \\
\hline Management & 4 & 5 & 4 & 13 \\
\hline Total & 31 & 35 & 31 & 97 \\
\hline
\end{tabular}


Table 2

Specific Strategy Topics Reported as Learned by Students in Three Semesters and Cumulative Count

\begin{tabular}{|c|c|c|c|c|}
\hline \multirow{2}{*}{$\begin{array}{l}\text { Strategy topics as } \\
\text { reported "learned" in } \\
\text { midterm exam }\end{array}$} & \multicolumn{4}{|c|}{ Number (\%) of students reporting topic as learned } \\
\hline & $\begin{array}{c}\text { Semester } 1(\mathrm{n}=31) \text { : } \\
\text { \# respondents }(\%)\end{array}$ & $\begin{array}{c}\text { Semester } 2(\mathrm{n}=35) \text { : } \\
\text { \# respondents }\end{array}$ & $\begin{array}{c}\text { Semester } 3(\mathrm{n}=31) \text { : } \\
\text { \# respondents }\end{array}$ & $\begin{array}{c}\text { Total respondents }(\mathrm{N}=97) \\
\text { over } 3 \text { semesters }\end{array}$ \\
\hline $\begin{array}{l}\text { Mission, Goals, Priorities } \\
\text { \& Values }\end{array}$ & $9(29 \%)$ & $16(35 \%)$ & $18(58.1 \%)$ & $43(41.7 \%)$ \\
\hline Strategy Formulation & $11(35.5 \%)$ & $20(57.1 \%)$ & $22(71.0 \%)$ & $53(51.4 \%)$ \\
\hline $\begin{array}{l}\text { SWOT Analysis } \\
\text { (Strengths, Weaknesses, } \\
\text { Opportunities, and } \\
\text { Threats) }\end{array}$ & $7(22.6 \%)$ & $8(22.9 \%)$ & $9(29.0 \%)$ & $24(23.3 \%)$ \\
\hline Strategy Implementation & $10(32.3 \%)$ & 15 (42.9\%) & $13(41.9 \%)$ & $38(36.9 \%)$ \\
\hline Strategy Evaluation & $9(29 \%)$ & $13(37.1 \%)$ & $14(45.2 \%)$ & $36(34.9 \%)$ \\
\hline
\end{tabular}

Note:

Students were allowed to list more than one topic as learned; hence the percentages do not total $100 \%$. 
Table 3

Number of Strategy Topics Reported as Learned by Students in Three Semesters and Cumulative Count

\begin{tabular}{lcccc}
\hline & \multicolumn{2}{c}{ Number of respondents } \\
\cline { 2 - 5 } $\begin{array}{c}\text { Number of Topics Students } \\
\text { Reported Learned }\end{array}$ & $\begin{array}{c}\text { Semester } 1 \\
(n=31)\end{array}$ & $\begin{array}{c}\text { Semester } 2 \\
(n=35)\end{array}$ & $\begin{array}{c}\text { Semester 3 } \\
(n=31)\end{array}$ & $\begin{array}{c}\text { Total over 3 } \\
\text { semesters }(N=97)\end{array}$ \\
\hline 0 Topics Reported Learned & $10(32.3 \%)$ & $9(25.7 \%)$ & $3(9.7 \%)$ & $22(22.7 \%)$ \\
\hline 1 Topic Reported Learned & $8(25.8 \%)$ & $4(11.4 \%)$ & $6(16.1 \%)$ & $17(17.5 \%)$ \\
\hline 2 Topics Reported Learned & $5(16.1 \%)$ & $7(20.0 \%)$ & $10(32.3 \%)$ & $22(22.7 \%)$ \\
\hline 3 Topics Reported Learned & $5(16.1 \%)$ & $7(20.0 \%)$ & $6(19.4 \%)$ & $15(15.5 \%)$ \\
\hline All 5 Topics Learned & $2(6.5 \%)$ & $7(20.0 \%)$ & $1(3.2 \%)$ & $3(3.1 \%)$ \\
\hline Total Number of Students & $1(3.2 \%)$ & $1(2.9 \%)$ & $31(100 \%)$ & $97(100 \%)$ \\
\hline
\end{tabular}


Table 4

\begin{tabular}{lcccc}
\hline Results Concerning Teacher Effectiveness Over Time & & \\
\hline $\begin{array}{l}\text { Semesters } \\
\text { Compared }\end{array}$ & $\begin{array}{c}\text { Null Hypothesis } \\
\text { for RQ2 }\end{array}$ & $\begin{array}{c}\text { Alternative Hypothesis } \\
\text { for RQ2 }\end{array}$ & $\begin{array}{c}\mathrm{Z} \\
\text { Score }\end{array}$ & $\begin{array}{c}\text { Significance at } \\
\mathrm{p} \leq 0.05\end{array}$ \\
\hline 1 and 2 & $\mathrm{p}_{2} \leq \mathrm{p}_{1}$ & $\mathrm{p}_{2}>\mathrm{p}_{1}$ & 0.94 & Not Significant \\
\hline 2 and 3 & $\mathrm{p}_{3} \leq \mathrm{p}_{2}$ & $\mathrm{p}_{3}>\mathrm{p}_{2}$ & 0.65 & Not Significant \\
\hline 1 and 3 & $\mathrm{p}_{3} \leq \mathrm{p}_{1}$ & $\mathrm{p}_{3}>\mathrm{p}_{1}$ & 1.64 & Significant at $\mathrm{p}=0.05$ \\
\hline
\end{tabular}

Note.

Where

$\mathrm{p}_{\mathrm{i}}=\quad$ Total number of concepts reported by all students as learned in semester $\mathrm{i}$ Number of students enrolled in semester "i" X 5 (number of strategy concepts) 
Table 5

Results of Research Question 3: Are Some Strategy Concepts Learned More by Students Through the WSE?

\begin{tabular}{|c|c|c|c|}
\hline Compared Concepts* & $\begin{array}{l}\text { Null (and alternative) } \\
\text { Hypothesis for RQ3 }\end{array}$ & Z Score & $\begin{array}{c}\text { Significance at } \\
\mathrm{p} \leq 0.05\end{array}$ \\
\hline Formulation \& Implementation & $\mathrm{p}_{\text {form }}=\mathrm{p}_{\mathrm{imp}}\left(\mathrm{p}_{\mathrm{form}} \neq \mathrm{p}_{\mathrm{imp}}\right)$ & 2.30 & $\mathrm{p}<0.008$ \\
\hline Formulation \& Evaluation & $\mathrm{p}_{\text {form }}=\mathrm{p}_{\text {eval }}\left(\mathrm{p}_{\mathrm{form}} \neq \mathrm{p}_{\mathrm{eval}}\right)$ & 2.15 & $\mathrm{p}<0.016$ \\
\hline Formulation \& MGPV & $\mathrm{p}_{\text {form }}=\mathrm{p}_{\mathrm{mgpv}}\left(\mathrm{p}_{\mathrm{form}} \neq \mathrm{p}_{\mathrm{mgpv}}\right)$ & 1.07 & Not Significant \\
\hline Formulation \& SWOT & $\mathrm{p}_{\text {form }}=\mathrm{p}_{\mathrm{swot}}\left(\mathrm{p}_{\mathrm{form}} \neq \mathrm{p}_{\mathrm{swot}}\right)$ & 3.54 & $\mathrm{p}<0.001$ \\
\hline MGPV \& SWOT & $\mathrm{p}_{\mathrm{mgpv}}=\mathrm{p}_{\mathrm{swot}}\left(\mathrm{p}_{\mathrm{mgpv}} \neq \mathrm{p}_{\mathrm{swot}}\right)$ & 2.31 & $\mathrm{p}<0.002$ \\
\hline
\end{tabular}

Notes.

Where $\quad \mathrm{p}_{\mathrm{i}}=$ the number of times students reported "i" concept in semester 3 number of students enrolled in semester 3

Legends: MGPV: Missions, goals, values and principles

SWOT: Strengths, weaknesses, opportunities and threats

* The most reported concept - Strategy Formulation - is compared with the remaining four concepts, and the least reported topic - SWOT - is compared with the second most learned topic, i.e., MGPV. 


\section{APPENDIX}

\section{WINTER SURVIVAL EXERCISE (WSE) AS USED BY JOHNSON AND JOHNSON (1982)}

\section{The Situation}

You have just crash-landed in the woods of North Minnesota and Southern Manitoba. It is 11:32 a.m. in mid-January. The small plane in which you were traveling has been completely destroyed except for the frame. The pilot and co-pilot have been killed, but no one else is seriously injured. The crash came suddenly before the pilot had time to radio for help or inform anyone of your position. Since your pilot was trying to avoid a storm, you know the plane was considerably off course. The pilot announced shortly before the crash that you were eighty miles northwest of a small town that is the nearest known habitation. You are in a wilderness area made up of thick woods broken by many lakes and rivers. The last weather report indicated that the temperature would reach minus twenty-five degrees in the daytime and minus forty at night. You are dressed in winter clothing appropriate for city wear - suits, pantsuits, street shoes, and overcoats. While escaping from the plane your group salvaged the fifteen items listed below. Your task is to rank these items according to their importance to your survival. You may assume that the number is the same as the number in your group and that the group has agreed to stick together. Winter Survival Ranking Form

Rank the following items according to their importance to your survival, starting with " 1 ” for the most important and proceeding to " 15 " for the least important:

Compress kit (with 28-ft., 2-in. gauze)

Sectional air map made of plastic

Ball of steel wool

30 feet of rope

Cigarette lighter (without fluid)

Family-size chocolate bar (one per person)

Loaded .45 caliber pistol

Flashlight with batteries

Newspaper (one per person)

Quart of 85-proof whiskey

Compass

Extra shirt and pants for each survivor

Two ski poles

Knife

Can of shortening

Background Information

Important note: None of the following background information should be given to participants until after they have completed the decision-making parts of the exercise.

Mid-January is the coldest time of the year in Minnesota and Manitoba. The first problem the survivors' face, therefore, is to preserve their body heat and protect themselves against its loss. This problem can be met by building a fire, minimizing movement and exertion, and using as much insulation as possible. The participants have just crash-landed. Many individuals tend to overlook the enormous shock reaction this has upon the human body, and the death of the pilot and co-pilot increases the shock. Decision making under such conditions is extremely difficult. Such a situation requires a strong emphasis upon the use of reasoning not only to make decisions, but also to reduce the fear and panic every person would naturally feel. Along with fear, shock reaction is manifested in the feelings of helplessness, loneliness, and hopelessness. These feelings have brought about more fatalities than perhaps any other cause in survival situations. Through the use of reasoning, hope can be generated. Certainly the state of shock means that movement of individuals should be at a minimum and that an attempt to calm them should be made.

Before taking off a pilot always has to file a flight plan. The flight plan contains the vital information regarding the flight, such as the course, speed, estimated time of arrival, type of aircraft, number of people on board, and so on. Search-and-rescue operations would begin shortly after the plane failed to arrive at its destination at its estimated time of arrival. The eighty miles to the nearest known town is a very long walk even under ideal conditions, particularly if one is not used to walking such distances. Under the circumstances of being in shock, 
dressed in city clothes, having deep snow in the woods, and a variety of water barriers to cross, to attempt to walk out would mean almost certain death from freezing and exhaustion. At the temperatures given, the loss of body heat through exertion is a very serious matter. Once the survivors have found ways in which to keep warm, their most immediate problem is to provide signaling methods to attract the attention of search planes and search parties. Thus, all the items the group has must be assessed according to their value in signaling the group's whereabouts. Winter Survival Answer Key

Rank the following items according to their importance to your survival, starting with " 1 " for the most important and proceeding to " 15 " for the least important:

\begin{tabular}{|c|c|}
\hline 11 & Compress kit (with 28-ft., 2-in. gauze) \\
\hline$\underline{14}$ & Sectional air map made of plastic \\
\hline$\underline{2}$ & Ball of steel wool \\
\hline$\underline{7}$ & 30 feet of rope \\
\hline$\underline{1}$ & Cigarette lighter(without fluid) \\
\hline$\underline{4}$ & Family-size chocolate bar (one per person) \\
\hline$\underline{9}$ & Loaded .45 caliber pistol \\
\hline$\underline{6}$ & Flashlight with batteries \\
\hline$\underline{8}$ & Newspaper (one per person) \\
\hline$\underline{13}$ & Quart of 85-proof whiskey \\
\hline$\underline{15}$ & Compass \\
\hline$\underline{3}$ & Extra shirt and pants for each survivor \\
\hline$\underline{12}$ & Two ski poles \\
\hline$\underline{10}$ & Knife \\
\hline$\underline{5}$ & Can of shortening \\
\hline
\end{tabular}

Winter Survival Exercise Scoring Explanation

The correct ranking of the survivors' items was made on the basis of information provided by Mark Wanig and supplemented from Rutstrum (1973). Wanig was an instructor for three years in survival training in the reconnaissance school in the $101^{\text {st }}$ Division of the U.S. Army and later an instructor on wilderness survival for four years at the Twin City Institute for Talented Youth. He is now conducting wilderness-survival programs for Minneapolis teachers.

Rank 1: Cigarette lighter (without fluid). The gravest danger facing the group is exposure to the cold. The greatest need is for a source of warmth and the second greatest need is for signaling devices. This makes building a fire the first order of business. Without matches something is needed to produce sparks to start a fire. Even without fluid the cigarette lighter can be used to produce sparks. The fire will not only provide warmth, it will also provide smoke for daytime signaling and firelight for nighttime signaling.

Rank 2: Ball of steel wool. To make a fire, a means of catching the sparks made by the cigarette lighter is needed. Steel wool is the best substance with which to catch a spark and support a flame, even if it is a little bit wet.

Rank 3: Extra shirt and pants for each survivor. Clothes are probably the most versatile items one can have in a situation like this. Besides adding warmth to the body they can be used for shelter, signaling, bedding, bandages, string when unraveled, and tinder to make fires. Even maps can be drawn on them. The versatility of clothes and the need for fires, signaling devices, and warmth make this item number three in importance.

Rank 4: Family-size chocolate bar (one per person). To gather wood for the fire and to set up signals, energy is needed. The Hershey bars would supply the energy to sustain the survivors for quite some time. Because they contain basically carbohydrates, they would supply energy without making digestive demands upon the body.

Rank 5: Can of shortening. This item has many uses - the most important being that a mirror-like signaling device can be made from the lid. After shining the lid with the steel wool, the survivors can use it to produce an effective reflector of sunlight. A mirror is the most powerful tool they have for communicating their presence. In sunlight, a simple mirror can generate 5 to 7 million candlepower. The reflected sunbeam can be seen beyond the horizon. Its effectiveness is somewhat limited by the trees but one member of the group could climb a tree and use the mirror to signal search planes. If the survivors have no other means of signaling, they would still have better than 80 percent chance of being rescued within the first twenty-four hours. Other uses for the item are as follows: The shortening can be rubbed on the body to protect exposed areas, such as the face, lips, and hands, from the cold. In desperation it could be eaten in small amounts. When melted into an oil the shortening is helpful 
in starting fires. Melted shortening, when soaked into a piece of cloth, will produce an effective candlewick. The can is useful in melting snow to produce drinking water. Even in the wintertime water is important as the body loses water in many ways, such as through perspiration, respiration, shock reactions, and so on. This water must be replenished because dehydration affects the ability to make clear decisions. The can is also useful as a cup.

Rank 6: Flashlight. Inasmuch as the group has little hope of survival if it decides to walk out, its major hope is to catch the attention of search planes. During the day the lid-mirror, smoke, and flags made from clothing represent the best devices. During the night the flashlight is the best signaling device. It is the only effective nightsignaling devices beside the fire. In the cold, however, a flashlight loses the power in its battery very quickly. It must therefore, be kept warm if it is to work, which means that it must be kept close to someone's body. The value of the flashlight lies in the fact that if the fire burns low or inadvertently goes out, the flashlight could be immediately turned on the moment a plane is heard.

Rank 7: Piece of rope. The rope is another versatile piece of equipment. It could be used to pull dead limbs of trees for firewood. When cut into pieces, the rope will help in constructing shelters. It can be burned. When frayed it can be used as tinder to start fires. When unraveled it will make good insulation from the cold if it is stuffed inside clothing.

Rank 8: Newspaper (one per person). The newspaper could be used for starting a fire much the same as the rope. It will also serve as an insulator; when rolled up and placed under the clothes around a person's legs or arms, it provides dead-air space for extra protection from the cold. The paper can be used for recreation by reading it, memorizing it, folding it, or tearing it. It could be rolled into a cone and yelled through as a signal device. It could also be spread around an area to help signal a rescue party.

Rank 9: .45-caliber pistol. This pistol provides a sound-signaling device. (The international distress signal is three shots fired in rapid succession.) There have been numerous cases of survivors going undetected because by the time the rescue party arrived in the area the survivors were too weak to make a loud enough noise to attract attention. The butt of the pistol could be used as a hammer. The powder from the shells will assist in fire building. By placing a small bit of cloth in a cartridge, emptied of its bullet, a fire can be started by firing the gun at dry wood on the ground. At night the muzzle blast of the gun is visible, which also makes it useful as a signaling device. The pistol's advantages are counterbalanced by its dangerous disadvantages. Anger, frustration, impatience, irritability, and lapses of rationality may increase as the group waits to be rescued. The availability of a lethal weapon is a real danger to the group under these conditions. Although it could be used for hunting, it would take a highly skilled marksman to kill an animal and then the animal would have to be transported through the snow to the crash area, probably taking more energy than would be advisable.

Rank 10: Knife. A knife is a versatile tool, but it is not too important in the winter setting. It could be used for cutting the rope into desired lengths, making shavings from pieces of wood for tinder, and many other uses could be thought up.

Rank 11: Compress kit (with gauze). The best use of this item is to wrap the gauze around exposed areas of the body for insulation. Feet and hands are probably the most vulnerable to frostbite, and the gauze can be used to keep them warm. The gauze can be used as a candlewick when dipped into melted shortening. It would also make effective tinder. The small supply of the gauze is the reason this item is ranked so low.

Rank 12: Ski poles. Although they are not very important, the poles are useful as a flagpole or staff for signaling. They can be used to stabilize a person walking through the snow to collect wood, and to test the thickness of the ice on a lakeshore or stream. Probably their most useful function would be as supports for a shelter or by the fire as a heat reflector.

Rank 13: Quart of 85-proof whiskey. The only useful function of the whiskey is to aid in fire building or as a fuel. A torch could be made from a piece of clothing soaked in the whiskey and attached to an upright ski pole. The danger of the whiskey is that someone might try to drink it when it is cold. Whiskey takes on the temperature it is exposed to, and a drink of it at minus thirty degrees would freeze a person's esophagus and stomach and do considerable damage to the mouth. Drinking it warm will cause dehydration. The bottle, kept warm, would be useful for storing drinking water.

Rank 14: Sectional air map made of plastic. This item is dangerous because it will encourage individuals to attempt to walk to the nearest town - thereby condemning them to almost certain death.

Rank 15: Compass. Because the compass may also encourage some survivors to try to walk to the nearest town, it too is a dangerous item. The only redeeming feature of the compass is the possible use of its glass top as a reflector of sunlight to signal search planes, but it is the least effective of the potential signaling devices available. That it might tempt survivors to walk away from the crash site makes it the least desirable of the fifteen items. 